\title{
A Robust Optimization Modeling for Mine Supply Chain Planning under the Big Data
}

\author{
Wenbo Liu \\ Department of Logistics Management, Liaoning Provincial College of Communications, Shenyang 110122, China \\ Correspondence should be addressed to Wenbo Liu; wenbo-315@163.com
}

Received 12 August 2021; Accepted 27 September 2021; Published 23 October 2021

Academic Editor: Rajesh Kaluri

Copyright () 2021 Wenbo Liu. This is an open access article distributed under the Creative Commons Attribution License, which permits unrestricted use, distribution, and reproduction in any medium, provided the original work is properly cited.

\begin{abstract}
With the rapid development of information technology, large-scale data is collected and stored, which provides a huge amount of information for decision-making. This paper focuses on the planning of mine supply chain under the big data. The mine supply chain usually contains three stages, which is mining, processing, and ore product transportation. This paper tackles the difficulty of variable cut-off grade by establishing a robust optimization model. To solve the robust optimization model, the nonlinear constraints in the model were linearized first. Then, the specific parameter values were determined through the employment of the hypothesis test in statistics, and the robust optimization model was solved finally. The analysis results show that the robust optimization model can be stabilized when the parameters are subject to disturbance. Finally, sensitivity analysis experiments are carried out for several parameters in the model to find out the influence of each parameter on the model. This paper combines mine supply chain planning with big data, which not only improves the production and transportation efficiency of ore products, but also reduces related costs.
\end{abstract}

\section{Introduction}

The steel industry is an important basic industry sector, which is the material base of developing national economy and national defense construction. It consumes large amount of iron ores in daily production and thus tends to maintain a high level of inventory. Meanwhile, the mining companies, which provide the iron ores suffer from the uncertainty of ore grade in mining and the market fluctuations in transportation. Based on this, it is necessary to establish a long-term, stable, and safe mine supply chain.

The mine supply chain under big data involves many links and contains a large number of relevant data or parameters. The emergence of big data has an unmistakable impact on the amount and speed of data processed in supply chains [1-3]. In the mine supply chain, the raw ores are extracted from multiple mining locations first, and each of the location might have different ore grade. Then, the raw ores are mixed to meet the ore grade requirements and then transport to the concentrating mills for processing. Finally, the ore products are transported through railway or sea transportation from the concentrating mills to the logistics centers. The demands of the final users are met by the accurate services of the logistics centers. During the whole mine supply chain, the ore grade is a key factor involved in the decision-making. For each mining location, based on the estimation of the natural ore grade, the manager must determine a cut-off grade to optimize the quality and quantity of the mined ore. Generally speaking, the higher the cut-off grade, the higher the ore quality while the lower the ore quantity, since the iron ore blocks with a natural ore grade lower than the cut-off grade is dumped as waste. The concentrating mill has a minimum ore grade for the raw ore, and the decision of the cut-off grades in multiple ore locations will be subject to the mining of the iron ore, as well as the corresponding processing, inventory, and transportation largely. In this paper, the variable cut-off grade, which varies in different time periods is considered, for the purpose of promoting the flexibility of the whole ore supply chain. Most of the previous research attaches importance to the solution to a single component of the mine supply chain, e.g., mining, processing, production, warehousing, or transportation. It is of great significance to study the whole mine supply chain, which is composed of the entire process of production, processing, 
inventory, and transportation. Mine supply chain planning is a data-driven process that focuses on developing plans to operate the supply chain efficiently and optimizing outcomes under given constraints [4]. Big data analysis tools such as optimization algorithms can help the supply chain to balance resource and to determine reasonable production planning capabilities, inventory levels, distribution capabilities, etc. $[5,6]$.

We followed the modeling methods of Liu et al. [7] and built a robust optimization model based on the important parameter of the cut-off grade. It was the logic of this paper that firstly determined the range of the parameter by the statistical analysis for the ore grade parameters through the employment of actual observation and exploration results, and then helped obtain the value of the relevant parameters by using hypothesis testing. Hypothesis testing with statistical significance is one of the most important methods of big data analysis. In addition, the objective function values obtained by the robust optimization model were compared with each other by carrying out numerical experiments, and then the verification for the stability and optimality of the robust optimization model was performed. As for robust optimization, it was able to address the problem of data uncertainty by guaranteeing the feasibility and optimality of the solution for the worst instances of the parameters. Through a number of numerical experiments, it was shown by the experimental results that the proposed robust optimization model was very stable under the circumstance of parameter perturbations.

This paper is aimed at coordinating mining, inventory, and transportation between all the aspects of the mine supply chain under the premise of considering relevant constraints and minimizing the total costs on the mining, blending, processing, inventory, and transportation of the supply chain. The main contribution of this paper is to integrate the key node enterprises in the mine supply chain, the optimization of its production and logistics systems, reduce or eliminate the phenomenon of unbalanced production, avoid the fluctuation of upstream and downstream, make the ore mining, processing, and transportation orderly, and realize the balanced development of supply and demand, so as to improve the overall benefit and efficiency of the mine supply chain. The research objects of this paper include monomer ore and other multimetal.

This paper is organized as follows: In Section 2, we review relevant literature. Section 3 describes our problem and constructs a robust optimization model. In Section 4, performance analysis and sensitivity analysis experiments are carried out for the robust optimization model. It is verified by the numerical experiments that the robust optimization model is able to meet the actual needs and obtain ideal results. Section 5 concludes the paper.

\section{Literature Review}

Ghiani et al. [8] defined the supply chain as "a complex logistics system in which raw materials are converted into finished products and then distributed to final users (consumers or companies)." The competitive advantage of supply chain management in various industries is realized though supply chain planning [9]. The supply chain planning involves many functional areas of procurement, production and distribution, and across strategic network planning, production planning and scheduling, purchasing and material requirement planning, and distribution and transport planning $[6,10]$. Brunaud and Grossmann [11] put forward the statement that some researchers carried out relevant studies on the supply chain modeling and optimization issues in a variety of industries. Nishi et al. [12] proposed a framework for distributed optimization of supply chain planning and coordination approach. Steinrücke [13] studied the practical problems of the global aluminum for supply chain network. Members of the aluminum for supply chain network are scattered around the world. They constructed a novel type of mixed-integer decision-making model, which can coordinate the production quantities and times of all supply chain members, in order to minimize the production and transportation cost of the whole supply chain. Vintró et al. [14] and Söderholm et al. [15] focused their research on green supply chain, such as the issues related to the society, environment, health, and safety. Apart from that, Kusi-Sarpong et al. [16] fixed their attention on the studies carried out for a framework and evaluation of Ghana's mining green supply chain practices. Azapagic [17] devoted himself to the development of a framework for the sustainable development of the mining and mining industry, in which economic, environmental, social, and other comprehensive indicators for the mining industry stakeholders are included.

Big data analysis is highly relevant to supply chain planning [5]. Optimization techniques can provide fundamental support to demand planning, production planning, inventory plans, and logistics planning by improving planning accuracy and flexibility [18-20]. The big data is collected from a wide range of diversified sources with various perspectives and data formats (i.e., variety) [21]. The digitization of supply chains [22] for better tracking of supply chains further highlights the role of big data analytics. He et al. [23] carried out some researches in the fields of big data analysis, which used dimensionality reduction algorithm of big data to quickly extract valuable parts from a huge amount of data and improve computational efficiency.

The production and distribution logistics planning in the open pit mine is known for its own unique features of the mining industry. It is the uncertainty available in the quality requirements of ore iron concentrates that challenges the choice about which grade of ore to mine. Newman et al. [24] review several decades of literature, including mine design, long-term and short-term production scheduling, equipment selection, and dispatching. Chen and Wang [25] constructed a linear programming model for integrated production planning for Canadian steel making company. The production plan is considered as an integrated process, including raw material procurement, semi-finished product procurement, capacity allocation, and finished product production and distribution. The purpose of the model is to optimize production planning based on production costs, product throughput rates, customer demands, sales prices, 
and facility capacities. Lagos et al. [26] consider a mining problem involving extraction and processing decisions under capacity constraints, and they solved the uncertainty of the ore grade.

The measure of dealing with uncertainty in supply chain optimization is usually completed by four common methods, stochastic programming (Azaron et al. [27]), fuzzy programming (Mitra et al. [28] and Lin et al. [29]), probabilistic programming (You and Grossmann [30]), and sensitivity analysis for instance. Robust optimization (Ben-Tal and Nemirovski [31]) is able to provide a framework to handle the uncertainty of parameters in the problems related to optimization within the category of a given set of bounded uncertainties, and the optimal solution can also be offered in an uncertain implementation. In addition, robust optimization can solve the model with uncertain parameters and realize the feasibility and optimality of the solution in the worst case of parameters. Bertsimas and Thiele [32] proposed a general robust methodology for the purpose of solving the problem of inventory with fixed costs and constraints of capacity for production/inventory. Gurnani et al. [33] focused on the analysis of a supply chain in assembly systems, where there was uncertainty in yields and demand. Zahiri et al. [34] proposed a robust model of demanddeterministic supply chain, which was composed of the centers for collection and distribution. Pishvaee et al. [35] fixed their attention on the study of a robust optimization model to manage uncertainty data for the problems existing in supply chain design. Vahdani et al. [36] proposed a reliable design model of supply chain in the circumstance of uncertainty. They present a dual-objective mathematical programming method, which can minimize the total cost and expected transportation cost under the failure of logistics network facilities. Additionally, Paydar et al. [37] proposed a MILP model for the used oil supply chain. Based on the uncertainty of oil collection, the robust optimization method was proposed by Mulvey et al. [38]. [32] Safaei et al. [39] proposed a mixed integer linear programming model, which can be used to optimize the paper and cardboard recycling network and solve demand uncertainty of the network by using the robust optimization. Jiao et al. [40] studied the design of sustainable closed-loop supply chain in a variety of uncertain circumstances. They also presented the datadriven approaches to generate robust closed-loop supply chain which can reduce uncertainty. It follows that most of the studies conducted previously put emphasis on the mechanism modeling and failed to set up the supply chain system from the data-driven perspective. Therefore, it is quite difficult to ensure the accuracy of the mechanism model, due to the subjective factors. In fact, data on relevant industries are easy to collect because it reflects the objective world.

\section{Problem Description and Model}

3.1. Problem Description. In recent years, with the continuous increase of global mining investment and production capacity, the overall supply capacity of ore has been significantly improved, which further promotes the continuous increase of global iron ore production and sea transport. The longterm stability of ore supply chain will attach great importance.

Macroscopically, the relevant nodes of the mine supply chain include mines, concentrating mills, logistics centers, and final users. The efficient operation of mine supply chain can realize the minimum total cost, including mining, processing, inventory, and transportation.

Different from general enterprises, mining enterprises extract ore resources from nature. Each ore body has its own characteristic; there are significant differences in mining technology, methods, and equipment. It is widely believed that ore grade is a very important factor in the process of mining. The production capacity of mine is affected by the grade distribution of ore body. The fluctuation of ore grade distributed in different orebodies will have a great influence on the output and quality of mined ore and then affect the subsequent processing. Therefore, the variable cut-off grade should be considered in the mining plan to allow for the flexibility of the mining stage under production capacity constraints. Due to the development of technology and industry, the quality of mineral requirements is more and more high, the need for mineral processing of raw ore, which is mineral processing. The mineral processing is the most important section in the whole production of mine. In addition, in order to meet the final users' demand for ore products in the supply chain, it is necessary to coordinate the mining and processing of ore. Therefore, the mine supply chain mentioned in this paper is different from the traditional single (multi) product and single (multi) period supply chain.

Figure 1 shows the framework of mine supply chain. Ore mined from multiple locations needs to be blended to meet the grade requirements of the concentrating mill. Then, the ore products from the concentrating mill will be transported to logistics centers in batches. According to demand, the logistics centers will store ore products of specific grades. Finally, the ore product will be transported from the logistics centers to the final users according to requirements.

The actual assumptions are as follows:

(1) Each mine has a number of ore extraction locations and can extract a variety of ore grade of raw ore, but the mining capacity of each mine is limited

(2) In each mine, raw ore from different locations is transported to the concentrating mill which belongs to mine for processing, and only one type of ore products is produced in the whole process

(3) Ore products of different grade are transported from the concentrating mills to logistics centers in batches, and ore products are then sent to final users in batches

In the next section, a robust optimization model is proposed.

3.2. Model. A robust optimization model is built based on the sets, parameters, and variables as follows.

Sets and parameters

$M$ : set of concentrating mills corresponding to mines 


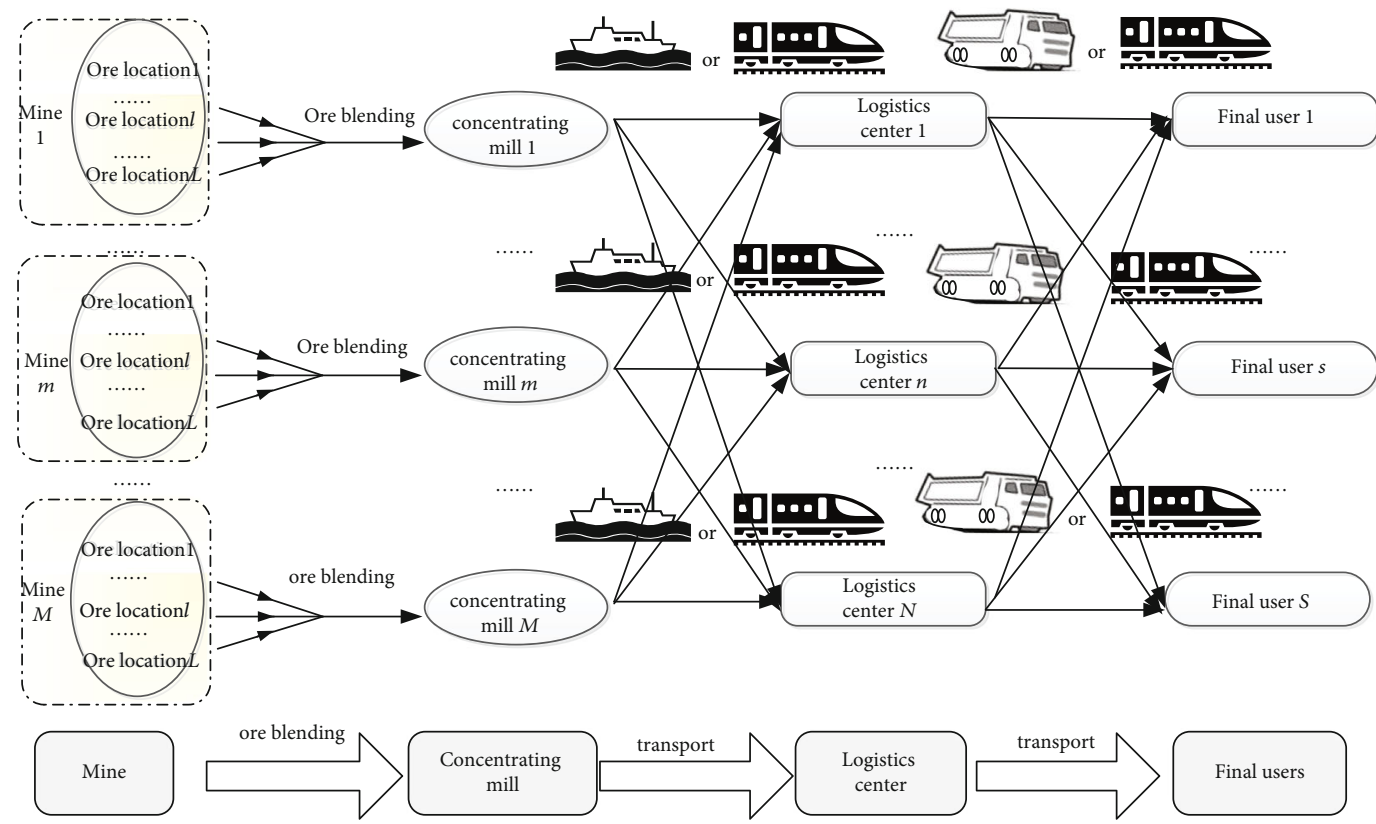

FIgURE 1: The framework of mine supply chain.

$N$ : set of logistics centers

$S$ : set of final users

$T$ : set of time periods

$L_{m}$ : number of mining sites in mine $m\left(l=1,2, \cdots,\left|L_{m}\right|\right)$

$O_{m}$ : number of optional cut-off grade of mine $m$ $\left(o=1,2, \cdots,\left|O_{m}\right|\right)$

$r_{m l}$ : consumption resource associated with the extraction of site $l$ of mine $m$

$C_{m l o}$ : unit exploitation cost of site $l$ of mine $m$ according the cut-off grade $o$

$P_{m}$ : unit processing cost of concentrating mill of mine $m$

$\mathrm{IO}_{m}$ : unit inventory cost of concentrating mill of mine $m$

$\mathrm{TR}_{m n}$ : unit transport cost of ore product from concentrating mill of mine $m$ to logistics center $n$

$\mathrm{ID}_{m n}$ : unit inventory cost at logistics center $n$ for the ore product from concentrating mill of mine $m$

$\mathrm{DC}_{n s}$ : unit transportation cost of ore product from logistics center $n$ to final user $s$

$\mathrm{SD}_{m n t}:$ start-up cost of ore products from concentrating mill of mine $m$ at logistics center $n$ in time period $t$

$\mathrm{ST}_{n s t}$ : start-up cost when ore products are transported from logistics center $n$ to final user $s$ in phase $t$

$U_{m t}$ : maximum storage of ore products at concentrating mill of mine $m$ in time period $t$

$L_{m t}:$ minimum storage of ore products at concentrating mill of mine $m$ in time period $t$

$H_{n t}^{\max }$ : maximum storage of ore products from all concentrating mill at logistics center $n$ in time period $t$

$D_{m s t}$ : demand of final user $s$ for ore products of mine $m$ in time period $t$

$g_{\text {mlot }}:$ the cut-off grade $o$, which is proportion of useful ore obtained from total mining, at the site $l$ of mine $m$ in time period $t$. In the mining process, for the reason of the error existing in exploration and the complex and variable geology, geomorphology, and grade of the mine, the actual value may deviate from the preestimated value, and the parameter $g_{\text {mlot }}$ can be random. Through statistical analysis by a large amount of actual mining data, it is observed that the parameter $\tilde{g}_{\text {mlot }}$ changes in the polyhedron (Khan and Asad [41]) and it can be expressed by the formula as follows: $\tilde{g}_{\text {mlot }} \in \Omega=\{g \mid H g \leq q\}$. Here, $H$ is uncertainty set matrix, and $q$ is parameter matrix

$g_{m}^{\min }:$ minimum selected grade of the concentrating mill of mine $m$

$j_{m}$ : productivity of ore products of concentrating mill of mine $m$

$\mathrm{SC}_{m l o t}$ : start-up cost of location $l$ of mine $m$ using the cut-off grade $o$ in time period $t$

$\mathrm{CA}_{m t}$ : production ability of mine $m$ in time period $t$

$\mathrm{PA}_{m t}$ : processing ability of concentrating mill of mine $m$ in time period $t$

$\mathrm{re}_{\text {mlot }}$ : unit consumption resource of location $l$ of mine $m$ using the cut-off grade $o$ in time period $t$

$M C_{m n t}:$ maximum transport ability of ore products of concentrating mill of mine $m$ to logistics center $n$ in time period $t$

$M$ : large positive number

Variables

$X_{m l o t}$ : amount of ore mined from location $l$ of mine $m$ using the cut-off grade $o$ in period time $t$

$X_{m t}$ : amount of ore blended in the concentrating mill of mine $m$ in time period $t$

$I_{m t}$ : inventory of ore products processed in concentrating mill of mine $m$ in time period $t$

$X_{m n t}$ : amount of ore products transported from concentrating mill of mine $m$ to logistics center $n$ in time period $t$

$I_{m n t}$ : inventory of ore products of mine $m$ in logistics center $n$ in time period $t$ 
$X_{\text {mnst }}:$ amount of the ore products of mine $m$ transported from logistics center $n$ to final user $s$ in time period $t$

$\lambda_{\text {mlot }}: 1$ if ore is mined from location $l$ of mine $m$ using the cut-off grade $o$ in time period $t, 0$ otherwise

$\omega_{m n t}: 1$ if ore products shipped from the concentrating mill of mine $m$ to logistics center $n$ in time period $t, 0$ otherwise

$\pi_{n s t}: 1$ if the ore products shipped from logistics center $n$ to final user $s$ in time period $t, 0$ otherwise

Formulation

$$
\begin{aligned}
\operatorname{Min} Z= & \sum_{m=1}^{M} \sum_{l=1}^{L_{m}} \sum_{o=1}^{O_{m}} \sum_{t=1}^{T} \mathrm{SC}_{m l o t} \lambda_{m l o t}+\sum_{m=1}^{M} \sum_{l=1}^{L_{m}} \sum_{o=1}^{O_{m}} \sum_{t=1}^{T} C_{m l o} x_{m l o t} \\
& +\sum_{m=1}^{M} \sum_{t=1}^{T} P_{m} X_{m t}+\sum_{m=1}^{M} \sum_{t=1}^{T} \mathrm{IO}_{m} I_{m t}+\sum_{m=1}^{M} \sum_{n=1}^{N} \sum_{t=1}^{T} \mathrm{SD}_{m n t} \omega_{m n t} \\
& +\sum_{n=1}^{N} \sum_{s=1}^{S} \sum_{t=1}^{T} \mathrm{ST}_{n s t} \pi_{n s t}+\sum_{m=1}^{M} \sum_{n=1}^{N} \sum_{t=1}^{T} \mathrm{TR}_{m n} X_{m n t} \\
& +\sum_{m=1}^{M} \sum_{n=1}^{N} \sum_{t=1}^{T} \mathrm{ID}_{m n} I_{m n t}+\sum_{m=1}^{M} \sum_{n=1}^{N} \sum_{s=1}^{S} \sum_{t=1}^{T} \mathrm{DC}_{n s} X_{m n s t}
\end{aligned}
$$

subject to

$$
\begin{gathered}
\sum_{l \in L_{m}}\left(r_{m l} \sum_{o \in O_{m}} \lambda_{m l o t}+\sum_{o \in O_{m}} \mathrm{re}_{m l o t} X_{m l o t}\right) \leq \mathrm{CA}_{m t}, \forall m \in M, t \in T \\
\sum_{l \in L_{m}} \sum_{o \in O_{m}} X_{m l o t} \leq \mathrm{PA}_{m t}, \forall m \in M, t \in T
\end{gathered}
$$

$$
\min _{\mathcal{E}^{T} H \geq x} \sum_{\varepsilon \geq 0} \sum_{l \in L_{m}} q \varepsilon_{m l o t}^{T} \geq g_{m}^{\min } \sum_{l \in L_{m}} \sum_{o \in O_{m}} X_{m l o t} \quad \forall m \in M, t \in T,
$$

$$
\begin{gathered}
\sum_{l \in L_{m}} \sum_{o \in O_{m}} X_{m l o t} \geq j_{m} X_{m t}, \forall m \in M, t \in T, \\
X_{m l o t} \leq M \lambda_{m l o t}, \forall m \in M, l \in L_{m}, o \in O_{m}, t \in T, \\
\sum_{o \in O_{m}} \lambda_{m l o t} \leq 1, \forall m \in M, l \in L_{m}, t \in T, \\
X_{m t}+I_{m, t-1}-\sum_{n \in N} X_{m n t}=I_{m t}, \forall m \in M, t \in T, \\
X_{m n t}+I_{m, n, t-1}-\sum_{s \in S} X_{m n s t}=I_{m n t}, \forall m \in M, n \in N, t \in T, \\
L_{m t} \leq I_{m t} \leq U_{m t}, \forall m \in M, t \in T, \\
\sum_{m \in M} I_{m n t} \leq H_{n t}^{\max }, \forall n \in N, t \in T \\
X_{m n t} \leq M C_{m n t} \omega_{m n t}, \forall m \in M, n \in N, t \in T, \\
\sum_{m \in M} X_{m n s t} \leq M \pi_{n s t}, \forall n \in N, s \in S, t \in T
\end{gathered}
$$

$$
\begin{gathered}
\sum_{n \in N} X_{m n s t} \geq D_{m s t}, \forall n \in N, s \in S, t \in T \\
X_{m l o t}, X_{m t}, I_{m t}, X_{m n t}, I_{m n t}, X_{m n s t} \geq 0, \forall m \in M, l \in L_{m}, o \in O_{m}, n \in N, s \in S, t \in T, \\
\lambda_{m l o t}, \omega_{m n t}, \pi_{n s t} \in\{0,1\}, \forall m \in M, l \in L_{m}, o \in O_{m}, n \in N, s \in S, t \in T .
\end{gathered}
$$

Equation (1) presents the objective function that minimizes the total cost of production, processing, inventory, transportation, and other related.

Constraint (2) indicates the tonnage of ore removed does not exceed the production ability. Constraint (3) indicates the tonnage of ore blended does not exceed the processing ability.

Constraint (4) ensures that ore processed in the concentrating mill meets the minimum ore grade requirements. Using the dual gap of linear programming is zero, the constraints (17)-(19) can be substituted for the constraint (4).

$$
g_{m}^{\min } \sum_{l \in L_{m}} \sum_{o \in O_{m}} X_{m l o t}-\sum_{l \in L_{m}} \sum_{o \in O_{m}} q \varepsilon_{m l o t}^{T} \leq 0 \quad \forall m \in M, t \in T,
$$

$$
\begin{gathered}
\varepsilon_{m l o t}^{T} H \geq X_{m l o t} \quad \forall m \in M, l \in L_{m}, o \in O_{m}, t \in T, \\
\varepsilon_{m l o t} \geq 0 \quad \forall m \in M, l \in L_{M}, o \in O_{m}, t \in T .
\end{gathered}
$$

Constraint (5) means to achieve the productive rate. Constraint (6) indicates logical constraints between variables related to mining. Constraint (7) requires that for each time period, only one ore cut-off grade can be selected. Constraints (8) and (9) represent the balance constraints. Constraints (10) and (11) ensure that the amount of ore products is required to be between the minimum and maximum inventory in each concentrating mill and logistics center. Constraints (12) and (13) represent the logical constraint. Constraint (14) means meeting the final user's demand for ore products in terms of time and quantity. Finally, constraints (15) and (16) enforce nonnegativity and integrality, as appropriate.

\section{Performance Analysis of Model}

The methods to deal with the problems of uncertain optimization mainly include analysis on sensitivity, fuzzy programming, stochastic programming, and robust optimization. The purpose of sensitivity analysis is to analyze the influence of uncertain parameter changes on the optimal solution. Sensitivity analysis can be used to study the stability of the optimal solution when the original data is inaccurate or has change, and it can also determine which parameters have a greater impact on the system or model. The robust optimization is derived from the traditional robust control theory, and it is regarded as a replacement of sensitivity analysis and stochastic programming. Robust optimization can limit the uncertain parameters within the disturbance range. The purpose is finding a solution that can be 
TABLE 1: The objective function value results of the robust optimization model.

\begin{tabular}{|c|c|c|c|c|c|}
\hline Numerical example (M-N-S-T) & $L_{m} / O_{m}$ & Mean (T RMB) & Variance & Maximum (T RMB) & Minimum (T RMB) \\
\hline \multirow{5}{*}{$3-2-2-3$} & I & 7.7698 & 0.0645 & 8.4266 & 7.3586 \\
\hline & II & 6.5342 & 0.0831 & 7.7921 & 6.3082 \\
\hline & III & 5.4109 & 0.1035 & 6.1293 & 5.4098 \\
\hline & IV & 5.4125 & 0.0792 & 6.0424 & 5.3905 \\
\hline & $\mathrm{V}$ & 6.8091 & 0.0592 & 8.0009 & 6.7298 \\
\hline \multirow{5}{*}{$4-3-3-5$} & $\mathrm{I}$ & 3.2983 & 0.0628 & 3.8723 & 3.0799 \\
\hline & II & 2.1532 & 0.0592 & 2.8901 & 2.0003 \\
\hline & III & 2.4103 & 0.0425 & 2.9904 & 2.0212 \\
\hline & IV & 2.1096 & 0.0691 & 2.7903 & 2.0109 \\
\hline & $\mathrm{V}$ & 2.0271 & 0.0701 & 2.6312 & 2.0002 \\
\hline \multirow{5}{*}{$6-5-6-8$} & I & 111.834 & 0.1463 & 145.342 & 101.093 \\
\hline & II & 85.853 & 0.1596 & 128.093 & 75.334 \\
\hline & III & 85.212 & 0.1394 & 130.984 & 76.987 \\
\hline & IV & 99.035 & 0.0809 & 140.242 & 87.092 \\
\hline & $\mathrm{V}$ & 90.352 & 0.1783 & 134.091 & 77.023 \\
\hline \multirow{5}{*}{$8-5-12-10$} & $\mathrm{I}$ & 289.355 & 0.0532 & 289.731 & 246.985 \\
\hline & II & 302.437 & 0.1903 & 380.921 & 251.243 \\
\hline & III & 250.876 & 0.3094 & 359.248 & 235.042 \\
\hline & IV & 274.902 & 0.0732 & 320.942 & 256.914 \\
\hline & $\mathrm{V}$ & 289.351 & 0.3190 & 341.253 & 268.933 \\
\hline
\end{tabular}

effectively resist the uncertainty and ensure the feasibility of the solution over the uncertain sets.

\subsection{Robust Optimization Analysis}

4.1.1. Hypothesis Testing. The parameter $\tilde{g}_{\text {mlot }}$ changes in the polyhedron as mentioned above and satisfies the following formula:

$$
\tilde{g}_{\text {mlot }} \in \Omega=\{g \mid H g \leq q\}
$$

Through the observation, derivation, and statistical analysis of multiple sets of uncertain parameters, the value in matrix $H$ is assumed to be -10 , and in matrix $q$, it is assumed to be -3 . In this section, hypothesis testing is used to verify whether the values of these two parameters are feasible.

The process is as follows:

(1) Propose reasonable original hypothesis $\left(\mathrm{H}_{0}\right)$ and alternative hypothesis $\left(\mathrm{H}_{1}\right)$ based on the problem

(2) Select suitable test statistics according to hypothetical characteristics

(3) Calculate the value of the test statistic from the sample observation at $\mathrm{H}_{0}$

(4) For a given of significance level $\alpha$, check the table or calculate the critical value through the distribution of test statistics and then get rejection domain and acceptance domain of $\mathrm{H}_{0}$
(5) The decision is to accept $\mathrm{H}_{0}$ when the value of the test statistic falls into the accepted domain, and otherwise, reject $\mathrm{H}_{0}$

Find the 20 samples from actual observations, due to the small sample size $(n<30)$, the $T$-test is used.

Establish two assumptions:

Original hypothesis $\left(H_{0}\right): \mu<0.3$

Alternative hypothesis $\left(H_{1}\right): \mu \geq 0.3$

$\mu$ represents the average value of the ratio of the useful ore component quality to the total ore quality obtained by selecting different mining cut-off grade at different periods of the mine.

Based on the original hypothesis, probability is obtained of the sample mean or more extreme mean. If the probability is large, the original hypothesis $\mathrm{H}_{0}$ is considered correct; otherwise, the original hypothesis is considered wrong, and the alternative hypothesis $\mathrm{H}_{1}$ is accepted.

Since the sample is normal distribution, the number of samples is 20 , and the statistic is the $t$-statistic, and the formula is as follows:

$$
t=\frac{\bar{x}-\mu}{S / \sqrt{n}} \sim t(n-1) .
$$

$\bar{x}$ is the sample average, $\mu$ is the ensemble average, $S$ is the sample standard deviation, and $n$ is the sample size.

This statistic is the $t$ distribution of the degree of freedom is $(n-1)$.

Actual observations were made on the ratio of the useful ore component quality to the total ore mining quality 
TABLE 2: The objective function value of different mining capacity and combination of the $L_{m}$ and $O_{m}$.

\begin{tabular}{|c|c|c|c|c|c|c|c|c|}
\hline Numerical example (M-N-S-T) & $L_{m} / O_{m}$ & $\begin{array}{c}U^{1} \\
(\mathrm{~T} \mathrm{RMB})\end{array}$ & $\begin{array}{c}U^{2} \\
(\mathrm{~T} \mathrm{RMB})\end{array}$ & $\begin{array}{c}U^{3} \\
(\mathrm{~T} \mathrm{RMB})\end{array}$ & $\begin{array}{c}U^{4} \\
(\mathrm{~T} \mathrm{RMB})\end{array}$ & $\begin{array}{c}U^{5} \\
(\mathrm{~T} \mathrm{RMB})\end{array}$ & $\begin{array}{c}U^{6} \\
(\mathrm{~T} \mathrm{RMB})\end{array}$ & $\begin{array}{c}U^{7} \\
(\mathrm{~T} \mathrm{RMB})\end{array}$ \\
\hline \multirow{5}{*}{$3-2-2-3$} & I & 7.6839 & 7.6923 & 7.7231 & 7.8423 & 7.8901 & 7.9021 & 7.9521 \\
\hline & II & 6.3369 & 6.3588 & 6.3730 & 6.4484 & 6.7816 & 6.8315 & 6.9723 \\
\hline & III & 5.3950 & 5.3950 & 5.3966 & 5.4326 & 5.5778 & 5.7789 & 5.8452 \\
\hline & IV & 5.3776 & 5.3776 & 5.3951 & 5.4094 & 5.4739 & 5.5349 & 5.5892 \\
\hline & $\mathrm{V}$ & 6.7086 & 6.7096 & 6.7452 & 6.9160 & 7.4193 & 7.3130 & 7.5295 \\
\hline \multirow{5}{*}{$4-3-3-5$} & I & 3.2654 & 3.2832 & 3.2937 & 3.3597 & 3.1307 & 3.3642 & 3.3958 \\
\hline & II & 2.1203 & 2.1203 & 2.1203 & 2.1216 & 2.1228 & 2.1394 & 2.1518 \\
\hline & III & 2.3111 & 2.3117 & 2.3121 & 2.3137 & 2.3206 & 2.3356 & 2.3813 \\
\hline & IV & 2.0817 & 2.0846 & 2.0891 & 2.0967 & 2.1044 & 2.2041 & 2.2402 \\
\hline & V & 2.0198 & 2.0198 & 2.0208 & 2.0228 & 2.0303 & 2.0621 & 2.0772 \\
\hline \multirow{5}{*}{$6-5-6-8$} & I & 109.147 & 109.589 & 110.184 & 110.870 & 111.021 & 111.068 & 112.098 \\
\hline & II & 83.989 & 84.152 & 84.456 & 84.792 & 85.411 & 85.896 & 86.231 \\
\hline & III & 83.895 & 84.008 & 84.229 & 84.399 & 84.712 & 85.023 & 85.932 \\
\hline & IV & 95.637 & 95.724 & 95.913 & 96.056 & 96.305 & 96.832 & 97.235 \\
\hline & $\mathrm{V}$ & 86.961 & 86.983 & 86.992 & 87.009 & 87.135 & 87.832 & 88.016 \\
\hline \multirow{5}{*}{$8-5-12-10$} & I & 265.303 & 266.831 & 269.233 & 270.665 & 272.116 & 274.359 & 283.012 \\
\hline & II & 291.983 & 292.580 & 293.404 & 293.878 & 294.387 & 295.346 & 296.063 \\
\hline & III & 238.284 & 238.423 & 238.535 & 238.666 & 238.783 & 239.012 & 239.983 \\
\hline & IV & 250.909 & 250.961 & 250.985 & 250.979 & 251.092 & 251.931 & 252.096 \\
\hline & $\mathrm{V}$ & 276.022 & 276.049 & 276.077 & 276.092 & 276.115 & 276.903 & 277.012 \\
\hline \multirow{5}{*}{$10-5-12-10$} & I & 340.973 & 341.329 & 341.772 & 342.006 & 342.366 & 343.001 & 343.893 \\
\hline & II & 334.036 & 334.357 & 334.877 & 335.255 & 335.768 & 335.982 & 336.023 \\
\hline & III & 284.802 & 284.851 & 284.857 & 284.878 & 285.912 & 286.012 & 288.022 \\
\hline & IV & 294.162 & 294.181 & 294.261 & 294.231 & 294.257 & 294.719 & 294.975 \\
\hline & $\mathrm{V}$ & 309.256 & 309.253 & 309.276 & 309.299 & 309.542 & 309.892 & 310.021 \\
\hline \multirow{5}{*}{$15-5-15-10$} & I & 537.261 & 537.321 & 537.982 & 537.998 & 538.231 & 539.012 & 539.823 \\
\hline & II & 432.421 & 432.498 & 432.512 & 432.832 & 432.987 & 433.053 & 433.875 \\
\hline & III & 421.905 & 421.998 & 422.012 & 422.429 & 422.498 & 423.712 & 423.891 \\
\hline & IV & 415.235 & 412.389 & 412.578 & 412.698 & 412.986 & 413.245 & 414.046 \\
\hline & $\mathrm{V}$ & 409.357 & 409.398 & 409.406 & 409.502 & 409.584 & 410.302 & 410.356 \\
\hline \multirow{5}{*}{$25-5-15-10$} & I & 589.599 & 589.904 & 590.052 & 590.146 & 590.250 & 590.457 & 590.602 \\
\hline & II & 508.920 & 508.874 & 508.922 & 508.930 & 509.103 & 509.521 & 510.903 \\
\hline & III & 509.103 & 509.428 & 509.754 & 509.981 & 509.995 & 510.325 & 510.932 \\
\hline & IV & 488.837 & 488.835 & 488.879 & 488.914 & 488.941 & 488.982 & 489.041 \\
\hline & $\mathrm{V}$ & 479.032 & 479.321 & 479.832 & 479.982 & 479.998 & 480.216 & 480.427 \\
\hline \multirow{5}{*}{$30-5-20-10$} & I & 673.923 & 674.022 & 675.921 & 675.995 & 676.023 & 676.901 & 679.313 \\
\hline & II & 665.321 & 665.492 & 665.792 & 666.912 & 666.998 & 670.321 & 679.352 \\
\hline & III & 650.384 & 650.822 & 650.982 & 651.342 & 652.094 & 653.926 & 654.932 \\
\hline & IV & 642.394 & 642.834 & 643.136 & 643.213 & 644.932 & 645.138 & 658.227 \\
\hline & $\mathrm{V}$ & 639.356 & 639.722 & 640.201 & 640.835 & 642.930 & 631.159 & 638.315 \\
\hline
\end{tabular}

obtained by selecting different cut-off grades at different sites at different periods, and 20 sample values were obtained, respectively:

$x_{1}, \cdots, \quad{ }_{20}=\{0.62,0.27,0.44,0.50,0.26,0.21,0.48,0.69$, $0.36,0.28,0.41,0.65,0.21,0.24,0.50,0.38,0.11,0.45,0.31$, $0.25\}$.
After calculation, the following results can be obtained: $\bar{x}=\sum_{i=1}^{20} x_{i} / 20=0.381, S=\sqrt{1 / 19 \sum_{i=1}^{20}\left(x_{i}-\bar{x}\right)^{2}} \approx 0.16$, and $t$ $=2.27$.

Taking the threshold is 0.025 , according to the table of quantile of $t$ distribution, the $t_{19}(0.025)=2.093$ can be 


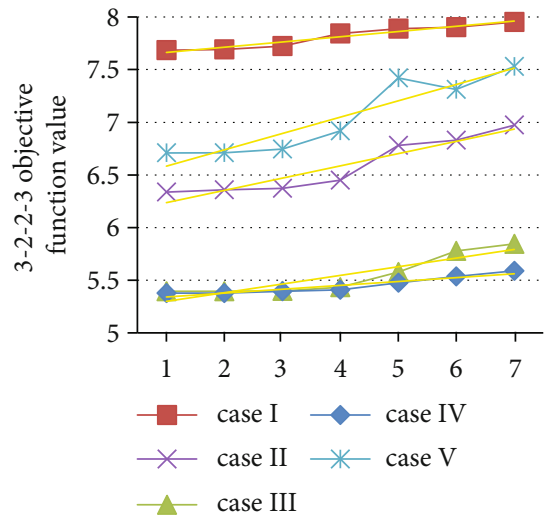

FIGURE 2: Sensitivity curve of the objective function value on the disturbance of mining capacity of example "3-2-2-3."

found. Since the absolute value of the $t$-statistic is 2.27 and falls within the "rejection domain," the original hypothesis is rejected and the alternative hypothesis is accepted. This shows that the sample average is significantly different from the overall average. So, it can be concluded that the average value grade of the useful ore component quality obtained by different cut-off grades at different periods at different sites to the total ore quality is greater than or equal to 0.3 .

Through the above statistical hypothesis testing, it can be finally determined that the value in the matrix $H$ is -10 , and the value in the matrix $q$ is -3 .

4.1.2. Solution of Robust Optimization Model. After determining the value range of $H$ and $q$, the results of $H$ and $q$ are substituted into Equations (17)-(19), the robust optimization model is directly solved by mainstream optimization software ILOG CPLEX V12.6.1, and then, the objective function value was obtained.

The purpose of numerical experiments is to verify the optimality and stability of the robust optimization model, so only small-scale examples are tested.

For the robust optimization model, the objective function values are obtained by 20 times disturbances.

Table 1 lists the mean, variance, maximum, and minimum values of the objective function values of the robust optimization model under disturbed 20 times for 4 examples. A different numbers of mines, logistics centers, final users, and time periods are considered, denoted by "M-NS-T," which are as follows: "3-2-2-3," "4-3-3-5," "6-5-6-8," and " $8-5-12-10$." Based on the combinations of mining sites $\left(L_{m}\right)$ and ore cut-off grades $\left(O_{m}\right)$, there are 5 cases in each group, i.e., case I: $L_{m}=\{3\}$ and $O_{m}=\{3\}$, case II: $L_{m}=\{5\}$ and $O_{m}=\{3\}$, case III: $L_{m}=\{10\}$ and $O_{m}$ $=\{5\}$, case IV: $L_{m}=\{15\}$ and $O_{m}=\{5\}$, and case V: $L_{m}=\{20\}$ and $O_{m}=\{5\}$.

The variance was a measure of the dispersion of a set of data. The results show that the variance of these examples was small, which proved that the fluctuation of examples was small as well. This also verifies that the robust optimization model was quite stable. Even if the actual mining grade differed greatly from expected, it can ensure the stability of the entire supply chain and meet demand.

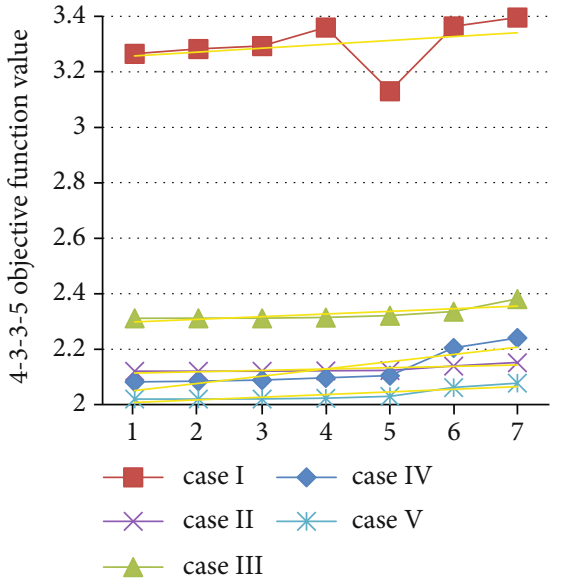

FIgURE 3: Sensitivity curve of the objective function value on the disturbance of mining capacity of example "4-3-3-5."

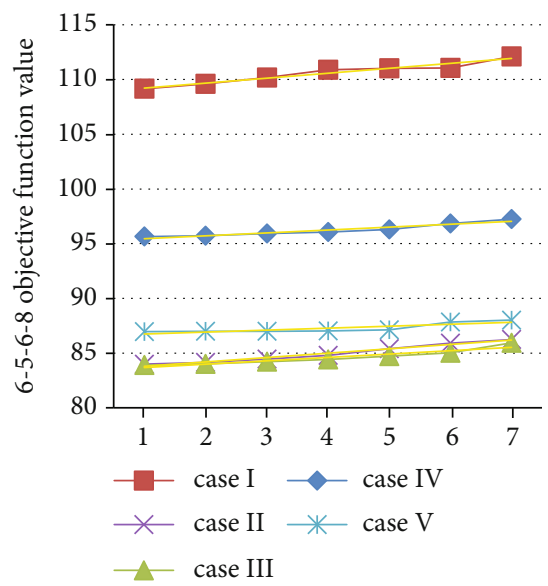

FIgURE 4: Sensitivity curve of the objective function value on the disturbance of mining capacity of example "6-5-6-8."

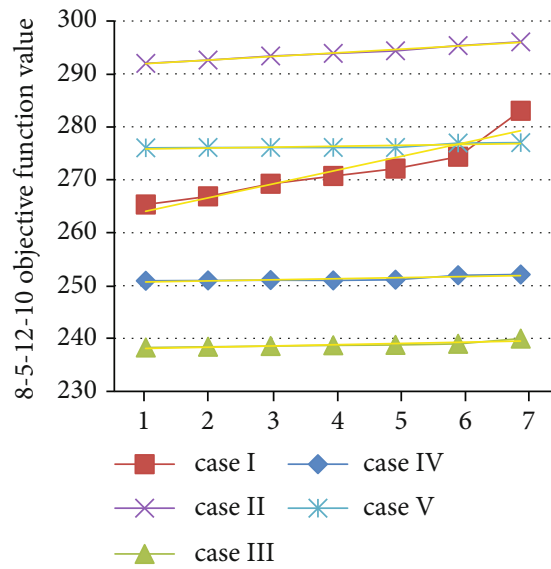

FIGURE 5: Sensitivity curve of the objective function value on the disturbance of mining capacity of example "8-5-12-10." 


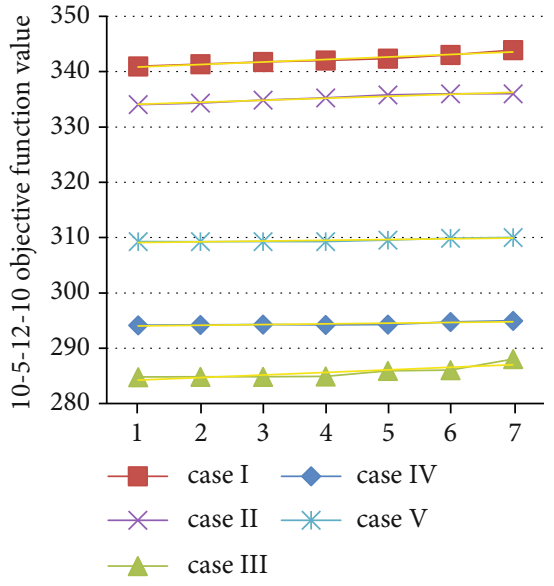

FIGURE 6: Sensitivity curve of the objective function value on the disturbance of mining capacity of example "10-5-12-10."

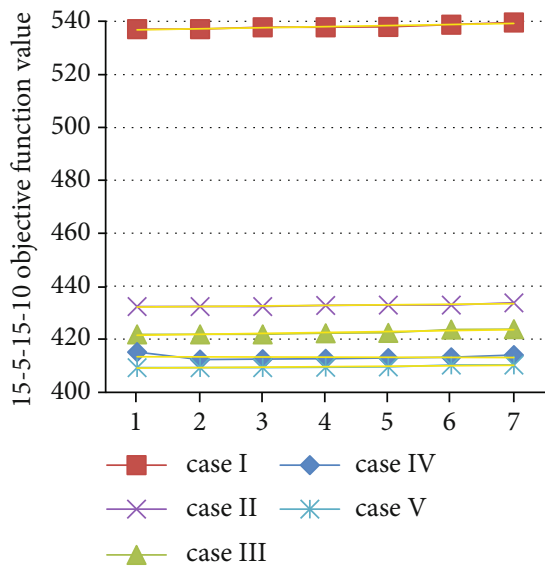

FIGURE 7: Sensitivity curve of the objective function value on the disturbance of mining capacity of example "15-5-15-10."

4.2. Sensitivity Analysis. The calculation examples in this section are similar to the previous section, and four groups are again added here, which are as follows: "10-5-12-10," "15-5-15-10," "25-5-15-10," and "30-5-20-10."

For each group of examples "M-N-S-T," the parameters of seven situations are set according to different mining capabilities under the corresponding mining site $L_{m}$ and the cut-off grade $O_{m}$, so $U^{1}, U^{2}, U^{3}, U^{4}, U^{5}, U^{6}$, and $U^{7}$ are shown, respectively. In these seven examples, other parameters remain unchanged, and only the mining capacity $\mathrm{CA}_{m t}$ changes. Table 2 lists the best objective function values for different mining capacities and mining site $L_{m}$ and the cut-off grade $O_{m}$.

The objective function value is obtained based on five different mining sites and combination of schemes under seven different mining capacities. The sensitivity curve of the whole objective function value after the disturbance of the mining capacity is plotted, as shown in Figures 2-9. The yellow line among the five broken lines is the linear trend line in each figure, and it represents the variation trend of objective function value.

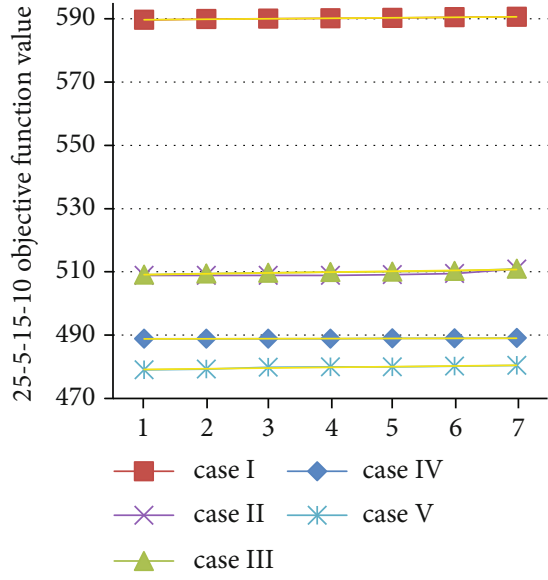

FIGURE 8: Sensitivity curve of the objective function value on the disturbance of mining capacity of example "25-5-15-10."

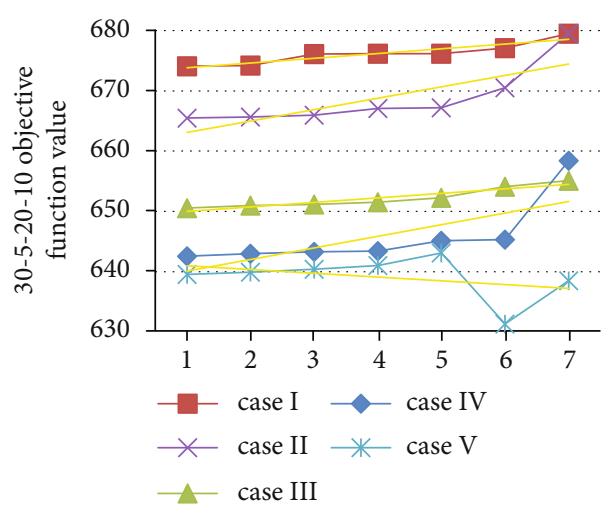

FIgURe 9: Sensitivity curve of the objective function value on the disturbance of mining capacity of example "30-5-20-10."

From Table 2 and sensitivity curves $1 \sim 8$, the following conclusions can be drawn:

(1) In terms of vertical comparison, for each example, as the number of mining sites and the programs increases, the overall objective function value shows a downward trend, indicating that the increase of the mining site and multiple alternatives can help reduce the total cost

(2) In terms of horizontal comparison, as far as the overall trend is concerned, with the same number of mines, logistics centers, final users, and time periods and the same set of mining sites and schemes, as the mining capacity decreases, the total cost increases (in some cases, the target value first decreases and then increases), which shows that as long as resources are allocated and used reasonably, the total cost can be reduced

\section{Conclusion}

In this paper, a robust optimization model was established for mine supply chain under big data, which includes mines, 
concentrating mills, logistics centers, and final users. The model not only considers the production details such as mining, grinding and separation, and ore blending, but also satisfies the intermediate links such as transportation and inventory and will ultimately meet the final users' requirements for ore product amount, ore grade, and time period. The model has universality and can be applied to different types of mines with different properties.

In this paper, the model is solved using the actual mine data from open pit mines, and the results have practical significance and value for mining enterprises. Through statistical analysis, it is obtained that the variable cut-off grade changes within a polyhedron. The analysis of the robust performance results shows that when the actual survey data deviates from the expected value, the robust optimization model built in this paper can be used to obtain the optimal solution, and even if the parameters are disturbed, the solution of the model is still stable. In conclusion, the robust optimization model proposed in this paper has stability and optimality.

Additionally, the sensitivity analysis was performed on the model, and the influence on the objective function value imposed by the parameter such as mining capacity, the change of the mining site, and the cut-off grade was obtained. Through the rational integration and allocation of resources, the production and logistics planning of open-pit mines can make more decisions that are reasonable.

In future research, we will continue to study in-depth changes in ore grades, hoping that there will be breakthroughs in big data analysis, and explore more static or dynamic influencing factors that may affect the entire mine production and logistics system, hoping to bring more profits to related enterprises in the mine supply chain.

\section{Data Availability}

The data used to support the findings of this study are included within the article.

\section{Conflicts of Interest}

The author declares no competing interest.

\section{Acknowledgments}

This work was supported by the Scientific Research Project of Education Department of Liaoning Province (L2019639).

\section{References}

[1] A. Gunasekaran, T. Papadopoulos, R. Dubey et al., "Big data and predictive analytics for supply chain and organizational performance," Journal of Business Research, vol. 70, pp. 308317, 2017.

[2] A. McAfee and E. Brynjolfsson, "Big data: the management revolution," Harvard Business Review, vol. 90, no. 90, pp. 60$68,2012$.

[3] M. A. Waller and S. E. Fawcett, "Data science, predictive analytics, and big data: a revolution that will transform supply chain design and management," Journal of Business Logistics, vol. 34, no. 2, pp. 77-84, 2013.

[4] Supply Chain Council, Supply-Chain Operations Reference Model, Revision 11.0, Supply Chain Council, 2012, http:// www.supply-chain.org.

[5] M. Brinch, "Understanding the value of big data in supply chain management and its business processes," International Journal of Operations \& Production Management, vol. 38, no. 7, pp. 1589-1614, 2018.

[6] H. Stadtler and C. Kilger, Supply Chain Management and Advanced Planning, Springer, Darmstadt, 3rd edition, 2005.

[7] W. Liu, D. Sun, and T. Xu, "Integrated production and distribution planning for the iron ore concentrate," Mathematical Problems in Engineering, vol. 2019, Article ID 7948349, 10 pages, 2019.

[8] G. Ghiani, G. Laporte, and R. Musmanno, Introduction to Logistics Systems Planning and Control, John Wiley \& Sons, 2004.

[9] P. Jonsson and J. Holmström, "Future of supply chain planning: closing the gaps between practice and promise," International Journal of Physical Distribution and Logistics Management, vol. 46, no. 1, pp. 62-81, 2016.

[10] Y. Mauergauz, Advanced Planning and Scheduling in Manufacturing and Supply Chains, Springer, Moscow, 2016.

[11] B. Brunaud and I. E. Grossmann, "Perspectives in multilevel decision-making in the process industry," Frontiers of Engineering Management, vol. 4, no. 3, pp. 256-270, 2017.

[12] T. Nishi, R. Shinozaki, and M. Konishi, "An augmented Lagrangian approach for distributed supply chain planning for multiple companies," IEEE Transactions on Automation Science and Engineering, vol. 5, no. 2, pp. 259-274, 2008.

[13] M. Steinrücke, "An approach to integrate productiontransportation planning and scheduling in an aluminium supply chain network," International Journal of Production Research, vol. 49, no. 21, pp. 6559-6583, 2011.

[14] C. Vintró, L. Sanmiquel, and M. Freijo, "Environmental sustainability in the mining sector: evidence from Catalan companies," Journal of Cleaner Production, vol. 84, pp. 155-163, 2014.

[15] K. Söderholm, P. Söderholm, H. Helenius et al., "Environmental regulation and competitiveness in the mining industry: permitting processes with special focus on Finland, Sweden and Russia," Resources Policy, vol. 43, pp. 130-142, 2015.

[16] S. Kusi-Sarpong, J. Sarkis, and X. Wang, "Assessing green supply chain practices in the Ghanaian mining industry: a framework and evaluation," International Journal of Production Economics, vol. 181, pp. 325-341, 2016.

[17] A. Azapagic, "Developing a framework for sustainable development indicators for the mining and minerals industry," Journal of Cleaner Production, vol. 12, no. 6, pp. 639-662, 2004.

[18] P. Russom, "Big data analytics," TDWI best practices report, vol. 19, The Data Warehousing Institute (TDWI), 2011.

[19] M. Seyedan and F. Mafakheri, "Predictive big data analytics for supply chain demand forecasting: methods, applications, and research opportunities," Journal of Big Data, vol. 7, no. 1, 2020.

[20] G. Wang, A. Gunasekaran, E. W. T. Ngai, and T. Papadopoulos, "Big data analytics in logistics and supply chain management: certain investigations for research and applications," International Journal of Production Economics, vol. 176, pp. 98-110, 2016. 
[21] R. G. J. Richey, T. R. Morgan, K. Lindsey-Hall, and F. G. Adams, "A global exploration of big data in the supply chain," International Journal of Physical Distribution \& Logistics Management, vol. 46, no. 8, pp. 710-739, 2016.

[22] G. Büyüközkan and F. Göçer, "Digital supply chain: literature review and a proposed framework for future research," Computers in Industry, vol. 97, pp. 157-177, 2018.

[23] H. S. Yuan, L. Shan, and G. Chao, "Research and implementation of dimension reduction algorithm in big data analysis," Artificial Intelligence and Security, 7th International Conference, pp. 14-26, 2021.

[24] A. M. Newman, E. Rubio, R. Caro, A. Weintraub, and K. Eurek, "A review of operations research in mine planning," Interfaces, vol. 40, no. 3, pp. 222-245, 2010.

[25] M. Chen and W. Wang, "A linear programming model for integrated steel production and distribution planning," International Journal of Operations \& Production Management, vol. 17, no. 6, pp. 592-610, 1997.

[26] G. Lagos, D. Espinoza, E. Moreno, and J. Amaya, "Robust planning for an open-pit mining problem under ore-grade uncertainty," Electronic Notes in Discrete Mathematics, vol. 37, pp. 15-20, 2011.

[27] A. Azaron, K. N. Brown, S. A. Tarim, and M. Modarres, "A multi-objective stochastic programming approach for supply chain design considering risk," International Journal of Production Economics, vol. 116, no. 1, pp. 129-138, 2008.

[28] K. Mitra, R. D. Gudi, S. C. Patwardhan, and G. Sardar, "Towards resilient supply chains: uncertainty analysis using fuzzy mathematical programming," Chemical Engineering Research and Design, vol. 87, no. 7, pp. 967-981, 2009.

[29] K. P. Lin, P. T. Chang, K. C. Hung, and P. F. Pai, “A simulation of vendor managed inventory dynamics using fuzzy arithmetic operations with genetic algorithms," Expert Systems with Applications, vol. 37, no. 3, pp. 2571-2579, 2010.

[30] F. You and I. E. Grossmann, "Design of responsive supply chains under demand uncertainty," Computers and Chemical Engineering, vol. 32, no. 12, pp. 3090-3111, 2008.

[31] A. Ben-Tal and A. Nemirovski, "Selected topics in robust convex optimization," Mathematical Programming, vol. 112, no. 1, pp. 125-158, 2008.

[32] D. Bertsimas and A. Thiele, "A robust optimization approach to inventory theory," Operations Research, vol. 54, no. 1, pp. 150-168, 2006.

[33] H. Gurnani, R. Akella, and J. Lehoczky, "Supply management in assembly systems with random yield and random demand," IIE Transactions, vol. 32, no. 8, pp. 701-714, 2000.

[34] B. Zahiri, M. Mousazadeh, and A. Bozorgi-Amiri, “A robust stochastic programming approach for blood collection and distribution network design," International Journal of Research in Industrial Engineering, vol. 3, no. 2, p. 1, 2014.

[35] M. S. Pishvaee, M. Rabbani, and S. A. Torabi, "A robust optimization approach to closed-loop supply chain network design under uncertainty," Applied Mathematical Modelling, vol. 35, no. 2, pp. 637-649, 2011.

[36] B. Vahdani, R. Tavakkoli-Moghaddam, M. Modarres, and A. Baboli, "Reliable design of a forward/reverse logistics network under uncertainty: a robust-M/M/c queuing model," Transportation Research Part E: Logistics and Transportation Review, vol. 48, no. 6, pp. 1152-1168, 2012.
[37] M. M. Paydar, V. Babaveisi, and A. S. Safaei, "An engine oil closed-loop supply chain design considering collection risk," Computers \& Chemical Engineering, vol. 104, pp. 38-55, 2017.

[38] J. M. Mulvey, R. J. Vanderbei, and S. A. Zenios, "Robust optimization of large-scale systems," Operations Research, vol. 43, no. 2, pp. 264-281, 1995.

[39] A. S. Safaei, A. Roozbeh, and M. M. Paydar, "A robust optimization model for the design of a cardboard closed-loop supply chain," Journal of Cleaner Production, vol. 166, pp. 1154-1168, 2017.

[40] Z. Jiao, L. Ran, Y. Zhang, Z. Li, and W. Zhang, "Data-driven approaches to integrated closed-loop sustainable supply chain design under multi-uncertainties," Journal of Cleaner Production, vol. 185, pp. 105-127, 2018.

[41] A. Khan and M. W. A. Asad, "A method for optimal cut-off grade policy in open pit mining operations under uncertain supply," Resources Policy, vol. 60, pp. 178-184, 2019. 